\title{
Leptomeningeal metastasis from melanoma emulating chronic subdural hematoma: a case report
}

\author{
Pawan Yadav, Govind Mangal, Uday Bhaumik, Sanjeev Agarwal, Poojan Thakor ${ }^{*}$ (C) and Vaibhav Lakhanpal
}

\begin{abstract}
Background: Melanoma is a disease in which the patient doesn't know about the primary lesion, and it has a propensity to metastases to any organ in the human body. Amongst melanoma, leptomeningeal metastasis has the least incidence.
\end{abstract}

Case presentation: In this case, we report a 56-year-old lady presenting with headache, recurrent vomiting and slurring of speech which on imaging was suggestive of chronic subdural hematoma which had led to surgical preparation but upon further examination, and radioimaging was found to be leptomeningeal metastasis from melanoma for which systemic therapy was started.

Conclusions: The concern is vigilance that is much needed in any case presenting in emergency. When the diagnosis is chronic subdural hematoma, it is followed by surgical treatment which is not done for leptomeningeal metastasis.

Keywords: Leptomeningeal metastases, Chronic subdural hematoma, Headache, Melanoma, Case report

\section{Background}

Leptomeninges means arachnoid and pia mater which covers the brain. Leptomeningeal metastasis (LM) is defined as the appearance of tumor cells in the leptomeninges or cerebrospinal fluid distant from the site of a primary tumor [1]. LM is diagnosed in $4-15 \%$ of patients with solid tumors [2]. Overall brain metastasis occur in $10-40 \%$ of patients with various systemic cancer [3]. Non-specific symptoms occur like headache and mental status changes, confusion, dementia, seizures and hemiparesis [2]. Due to its non-specific presentation and low incidence, it is not taken into consideration commonly against chronic subdural hematoma. This can lead to disastrous complications for the patients. Here, one such case is reported which presented as a chronic

*Correspondence: poojanthakor@gmail.com

Department of Neurosurgery and General Surgery, Geetanjali Medical College, Udaipur, Rajasthan 313001, India subdural hematoma but was in actuality leptomeningeal metastasis.

\section{Case presentation}

A 56-year-old female presented in emergency department with chief complains of headache, recurrent vomiting and slurring of speech since 15 days. There was no history of trauma. On examination, patient was conscious, oriented and telling her name, following verbal commands and moving all four limbs. She was referred to our institute with above complaints and with computed tomography (CT) scan inferring acute on chronic subdural hematoma in the right temporo-parietal region with mass effect and effacement of the ipsilateral ventricle and midline shift towards the left by $9.0 \mathrm{~mm}$ likely to be chronic subdural hematoma (Fig. 1). This led to surgical preparation as there was mass effect, however the presence of one more hypodense collection on CT, led to some doubt due to which an MRI brain was planned. This showed dural thickening with associated extra axial 


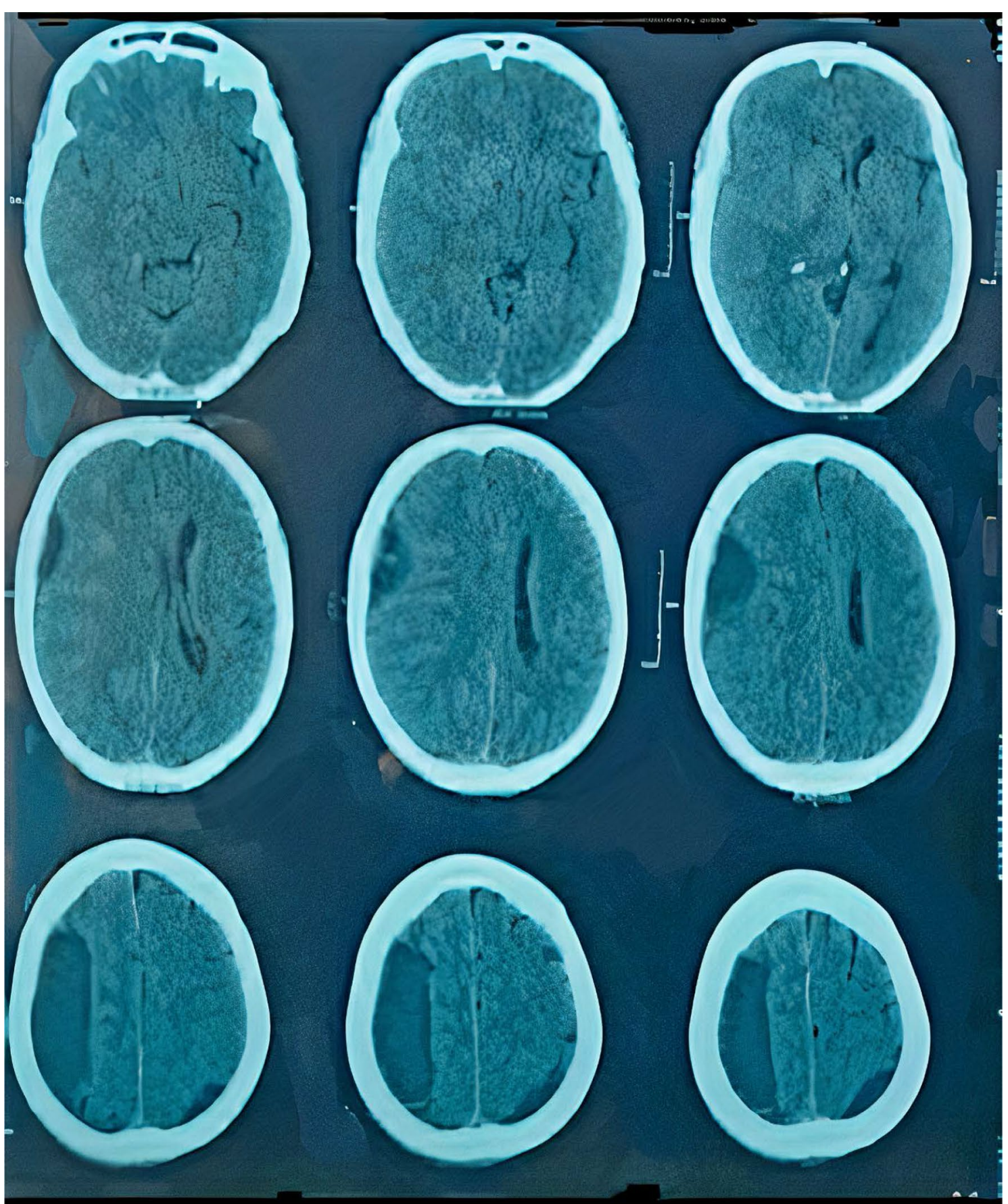

Fig. 1 CT scan brain: right temporal, parietal hypodense lesion and left parietal lesion

hypodense collection in right fronto-temporo-parietal region causing parietal effacement of right lateral ventricle and midline shift of $9 \mathrm{~mm}$ towards the left side which was likely to represent a metastatic lesion (Fig. 2). There was a similar but smaller extra-axial cystic collection in the left parietal region and a lytic lesion in the right parietal bone. This prompted a detailed physical examination on which a few enlarged lymph nodes were palpated in the right inguinal region which were not known to the patient. Ultrasound-guided cytology was done from the right inguinal lymph node. Medical oncology consultancy was done which advised for above cytology, 

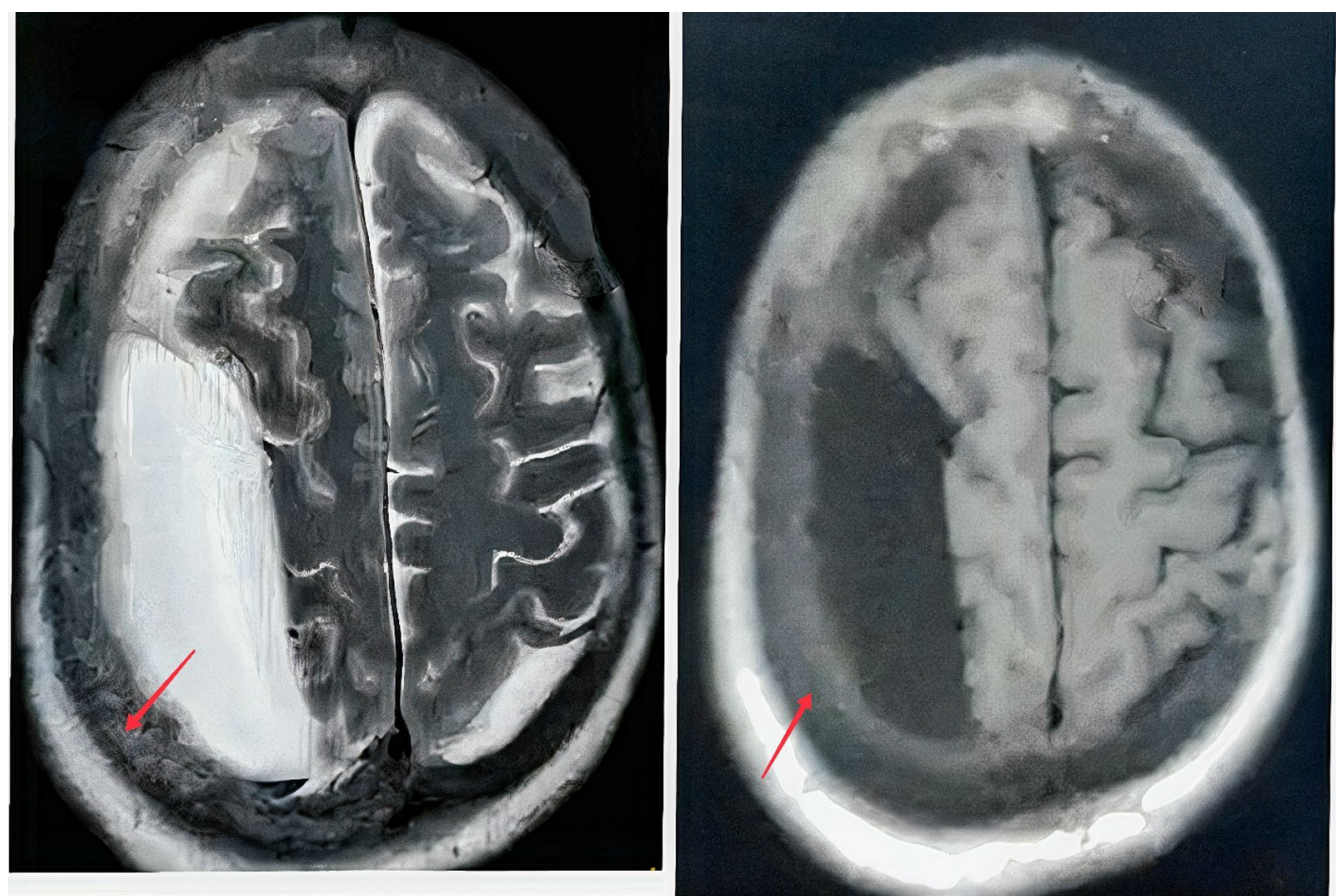

Fig. 2 MRI brain showing T2 and T1 images-right temporal, parietal hypodense lesion and left parietal lesion with dural thickening (arrow)

and it was suggestive of metastatic carcinoma which was sent for immunohistochemistry, and its results showed melanoma. On further workup, CT chest revealed an abnormal soft tissue thickening in right apical and supraclavicular region. Sclerotic lesions were seen in thoracic vertebrae number $1,8,9,12$ and lumbar vertebrae number $1,2,3$. All these findings were suggestive of metastatic melanoma disease. The patients clinical condition did not deteriorate, and she was started on antiepileptics and systemic therapy as per the medical oncologist.

\section{Discussion}

Metastasis to the brain can be in the brain parenchyma or the meninges covering it. The later is known as leptomeningeal metastasis and can be from extraneural or intraneural primary site [4]. It is also known as neoplastic meningitis and is mostly a late-stage complication of systemic cancers. Overall incidence is $4-15 \%$ [2].

Systemic cancer most commonly involving LM are breast cancer $(\mathrm{BC})$ followed by non-small cell lung cancer (NSCLC) and melanoma. The incidence of LM in BC, NSCLC and melanoma is $5 \%, 11 \%$ and $20 \%$, respectively [5-9]. Central nervous system (CNS) involvement is seen clinically in $30 \%$ of patients with melanoma and as high as $75 \%$ at autopsy [10]. The increased incidence of LM is due to more effective diagnostic modalities, adjuvant and salvage systemic therapies and non-effective chemotherapy to these metastatic cells due to the blood brain barrier leading to a prolongation of survival and late metastatic spread to the CNS [4].

Tumor cells pathway to the meninges can be different in which the most common form of spread is hematogenous followed by lymphatic, direct, choroid, de novo and iatrogenic [4]. The most affected areas are basilar cisterns and cauda equina [2].

LM manifests as a multifocal constellation of neurologic signs and symptoms. Common symptoms include cranial nerve deficits, radicular pain, headache, back pain, visual disturbances, diplopia, hearing loss, onset of psychiatric disorders, seizures and cauda equina syndrome [11]. Headache and confusion were common cerebral symptoms at presentation, with headache occurring in 39\% of patients [12]. A high index of suspicion needs to be entertained to make the diagnosis of LM. Due to nonspecific and pleomorphic presentations, other diagnoses are entertained like primary brain cancer, chronic meningitis, paraneoplastic syndromes and subdural hematoma.

Amongst the diagnostic modalities, magnetic resonance imaging (MRI) with gadolinium enhancement is the radiologic technique of choice. The most frequent MRI findings are subarachnoid and parenchymal enhancing nodules and diffuse or focal pial enhancement. The sensitivity of MRI varies from 20 to $91 \%$. CT is of limited value in the diagnosis of LM. The sensitivity of CT scan is estimated at $23-38 \%$, and it mostly shows hypodense lesions [4]. One must be able to differentiate 
chronic subdural hematoma from LM which can be our first diagnosis when the primary lesion is not known and patient presents with non-specific symptoms and a hypodense lesion with mass effect.

Leptomeningeal disease is difficult to treat, with generally poor outcomes. Primary treatment goals include improvement of the patients neurological deficits and quality of life, while avoiding toxicity. Pain relief is required for headaches, back and radicular pain and is based on the use of analgesics of increasing efficacy from acetaminophen to opioids. Seizures are treated with antiepileptic drugs. Surgery in LM is used for management of raised intracranial pressure requiring ventriculoperitoneal shunting (VPS) [2]. Intra cerebrospinal fluid (CSF) Methotrexate, Ara-C, cytarabine, Thiotepa can be used but showed less effectiveness [2].

Systemic treatments also showed modest response in BC, NSCLC and melanoma related LM [4]. In melanoma, intensive schedule of combinatorial temozolomide, ipilimumab, vermurafenib, dabrafenib or trametinib can be used [2]. Surgical excision of LM is not a treatment modality.

Without treatment, the median overall survival of patients with LM is approximately 6 weeks [2]. Despite advances, survival remains poor after diagnosis of leptomeningeal involvement, averaging around 3-6 months [11]. Melanoma related LM has the worst prognosis of all solid tumor related LM with median survivals between 10 weeks and 4 months [13-15].

\section{Conclusions}

Metastasis of melanoma to the leptomeninges can have a non-specific presentation which is encountered in our case. Moreover, the patient may have no knowledge of primary lesion, and this can have catastrophic consequences if not diagnosed correctly as the prognosis is very poor. Systemic therapy is the treatment of choice in malignant melanoma but has a dismal response and any valiant step if misdirected can add morbidity and mortality to the patient.

The patient was satisfied with the overall treatment and was obliged to the team of doctors.

\footnotetext{
Abbreviations

LM: leptomeningeal metastasis; CT: computed tomography; BC: breast cancer; NSCLC: nonsmall cell lung cancer; CNS: central nervous system; MRI: magnetic resonance imaging; VPS: ventriculoperitoneal shunting; CSF: cerebrospinal fluid.
}

\section{Acknowledgements}

Not applicable.

\section{Authors' contributions}

GM: admitted, investigated the case. UB: admitted, investigated the case. SA: investigated the case. PY: writing the case report. PT: writing and editing the case report. VL: revising, editing, writing the case report. All authors read and approved the final manuscript.

\section{Funding}

The authors are the source of funding.

Availability of data and materials

Not applicable.

\section{Declarations}

Ethics approval and consent to participate

Not applicable.

\section{Consent for publication}

An informed written consent was taken from the patient for reporting this case and the accompanying images.

\section{Competing interests}

The authors declare that they have no competing interests.

Received: 26 February 2021 Accepted: 11 September 2021

Published online: 30 December 2021

\section{References}

1. Kesari S, Batchelor TT. Leptomeningeal metastases. Neurol Clin. 2003;21(1):25-66

2. Taillibert S, Chamberlain MC. Leptomeningeal metastasis. Handb Clin Neurol. 2018;149:169-204. https://doi.org/10.1016/B978-0-12-811161-1. 00013-X.

3. D'Andrea G, Palombi L, Minniti G, Pesce A, Marchetti P. Brain metastases: surgical treatment and overall survival. World Neurosurg. 2017;97:169-77. https://doi.org/10.1016/j.wneu.2016.09.054.

4. Le Rhun E, Taillibert S, Chamberlain MC. Carcinomatous meningitis: leptomeningeal metastases in solid tumors. Surg Neurol Int. 2013;4(Suppl 4):S265.

5. Shapiro WR, Posner JB, Ushio Y, Chemik NL, Young DF. Treatment of meningeal neoplasms. Cancer Treat Rep. 1977;61(4):733-43.

6. Amer MH, Al-Sarraf M, Baker LH, Vaitkevicius VK. Malignant melanoma and central nervous system metastases: incidence, diagnosis, treatment and survival. Cancer. 1978;42(2):660-8. https://doi.org/10.1002/10970142(197808)42:2\%3c660::aid-cncr2820420237\%3e3.0.co;2-e.

7. Yap HY, Yap BS, Tashima CK, Distefano A, Blumenschein GR. Meningeal carcinomatosis in breast cancer. Cancer. 1978;42:283-6.

8. Rosen ST, Aisner J, MakuchRW MMJ, Ihde DC, Whitacre M, et al. Carcinomatous leptomeningitis in small cell lung cancer: a clinicopathologic review of the National Cancer Institute experience. Medicine (Baltimore). 1982:61:45-53.

9. Wasserstrom WR, Glass JP, Posner JB. Diagnosis and treatment of leptomeningeal metastases from solid tumors: experience with 90 patients. Cancer. 1982;49(4):759-72. https://doi.org/10.1002/1097-0142(19820215) 49:4\%3c759::aid-cncr2820490427\%3e3.0.co;2-7.

10. Smalley KS, Fedorenko IV, Kenchappa RS, Sahebjam S, Forsyth PA. Managing leptomeningeal melanoma metastases in the era of immune and targeted therapy. Int J Cancer. 2016;139:1195-201. https://doi.org/10. 1002/ijc.30147.

11. Nayar G, Ejikeme T, Chongsathidkiet P, Elsamadicy AA, Blackwell KL, Clarke JM, Lad SP, Fecci PE. Leptomeningeal disease: current diagnostic and therapeutic strategies. Oncotarget. 2017;8(42):73312-28. https://doi.org/ 10.18632/oncotarget.20272. 
12. Clarke JL. Leptomeningeal metastasis from systemic cancer. Continuum (Minneap Minn). 2012;18(2):328-42. https://doi.org/10.1212/01.CON. $0000413661.58045 . e 7$

13. Chamberlain MC, Kormanik PA, Barba D. Complications associated with intraventricular chemotherapy in patients with leptomeningeal metastases. J Neurosurg. 1997;87(5):694-9. https://doi.org/10.3171/jns.1997.87.5. 0694.

14. Brem SS, Bierman PJ, Black P, Blumenthal DT, Brem H, Chamberlain MC, et al. National comprehensive cancer network central nervous system cancers: clinical practice guidelines in oncology. J Natl Compr Canc Netw. 2005;3(5):644-90. https://doi.org/10.6004/jnccn.2005.0038.
15. Harstad L, Hess KR, Groves MD. Prognostic factors and outcomes in patients with leptomeningeal melanomatosis. J Neurooncol. 2008:10:1010-8.

\section{Publisher's Note}

Springer Nature remains neutral with regard to jurisdictional claims in published maps and institutional affiliations.

\section{Submit your manuscript to a SpringerOpen ${ }^{\odot}$ journal and benefit from:}

- Convenient online submission

- Rigorous peer review

- Open access: articles freely available online

- High visibility within the field

- Retaining the copyright to your article

Submit your next manuscript at $\boldsymbol{\nabla}$ springeropen.com 